Journal of Thermal Engineering, Vol. 7, No. 3, pp. 635-649, March, 2021

Yildiz Technical University Press, Istanbul, Turkey

\title{
PHYSICAL EFFECTS OF VARIABLE FLUID PROPERTIES ON GASEOUS SLIP- FLOW THROUGH A MICRO-CHANNEL HEAT SINK
}

\author{
Rajan Kumar1,*
}

\begin{abstract}
Physical effects induced in micro-convective gaseous slip-flow due to variation in fluid properties are numerically examined in this paper. The problem is particularly simulated for slip-flow through a micro-channel heat sink (MCHS) having constant heat flux supplied from the wall under hydrodynamically and thermally fully developed flow (FDF) conditions. It is observed that the Nusselt number $(\mathrm{Nu})$ for slip-flow is significantly higher than the no-slip-flow condition and $\mathrm{Nu}$ is significantly affected due to variable fluid properties (VFP). Four different cases of VFP are studied in order to investigate their effects individually. Pressure and temperature dependent density $(\rho(p, T)$ ) variation flattens the axial velocity profile in radial direction $(u(r))$ profile which promotes fastermoving particles close to the wall which considerably enhances $\mathrm{Nu}$. The incorporation of temperature-dependent viscosity $(\mu(T))$ variation marginally enhances $\mathrm{Nu}$ along the flow. Incorporation of temperature-dependent thermal conductivity $(k(T))$ variation highly augments $N u$ due to higher $\rho$ and higher $k$ fluid near to the wall and the incorporation of temperature-dependent specific heat at constant pressure $\left(\mathrm{C}_{\mathrm{p}}(T)\right)$ variation reduces $N u$ due to lower $k$ fluid near to the wall. The investigation also shows that the pressure drop significantly deviates from no-slip to slip condition. Furthermore, the effects of VFP on the gauge static pressure drop $\left(\Delta p_{\mathrm{g}}\right)$ and slip velocity are also examined. The incorporation of $\mu(T)$ and $k(T)$ variations trivially affects the $\Delta p_{\mathrm{g}}$ and slip velocity. However, the incorporation of $\mathrm{C}_{\mathrm{p}}(T)$ variation significantly affects the $\Delta p_{\mathrm{g}}$ and slip velocity.
\end{abstract}

Keywords: Micro-Convection, Variable Fluid Properties, Nusselt Number, Slip-Flow

\section{INTRODUCTION}

Gas micro-convection is an important active research area in transport phenomena since it is the basis for a broad range of miniaturized high-performance applications like Micro-Electro-Mechanical Systems (MEMS) and Nano-Electro-Mechanical Systems (NEMS). Many practical devices like ducts, valves, pumps, turbines, heat sinks, etc. have been shrunk towards the microscale. The characteristic size involved in such applications can vary from 1 $\mathrm{mm}$ to less than 1 micron. Microscale devices are finding an important place in our day-to-day lives; however, the fundamental science at the microscale is still not well known. The main problem to expect the flow through microand nano-scale channels can be attributed to the rarefaction effects which take place in the flow when the continuum approach breaks down as the characteristic length of the flow becomes comparable to the mean free path between molecules. The physical effects induced due to rarefaction influence the heat transfer (HT), velocity profile, and pressure drop $(\Delta p)$ in the channels [1]. The Knudsen number $(K n)$ is a measure of the degree of rarefaction which is defined as the ratio of the molecular mean free path $(\lambda)$ to the characteristic length scale of the system. The microscale gas flow regimes can be classified into different categories according to the value of $K n$, which can also be expressed in terms of Mach number (Ma) and Reynold number $(R e)$ as [2, 3]: $K n=\sqrt{\gamma \pi / 2} M a / R e$, where $\gamma$ is the ratio of specific heats, $M a$ is Mach number; $M a=u_{\mathrm{m}} / c$, and $R e$ is Reynolds number; $R e=\rho_{\mathrm{m}} \cdot u_{\mathrm{m}} \cdot D / \mu_{\mathrm{m}}$. The different categories are as follows:

(1) $\mathrm{Kn}<10^{-3}$, continuum flow

(2) $10^{-3}<K n<0.1$, slip-flow

(3) $0.1<K n<10$, transition flow

(4) $K n>10$, free molecular flow

This paper was recommended for publication in revised form by Regional Editor Mohammad Rahimi-Gorji

${ }^{1}$ Department of Mechanical Engineering, Dr B R Ambedkar National Institute of Technology Jalandhar, Punjab-144011, India

${ }^{*} E$-mail address: rajank@nitj.ac.in

Orcid id: 0000-0002-9929-5915

Manuscript Received: 22 February 2019, Accepted 14 May 2019 
The $K n$ indicates the significant length scale, which could be set either by a flow feature with near molecular dimensions or the dimension of the device [4]. For most MEMS flow applications working close to atmospheric situations, the $K n$ values are found in the slip and early transition regimes [5]. In micro-convection, the temperature gradients across and along the flow are very steep, therefore, the gradients of fluid property variations (FPV) are also very steep which extremely affects the micro-convection characteristics [6]. The literature review is divided into two categories; (1) review based on slip-flow (2) review based on variations in fluid properties.

\section{LITERATURE REVIEW ON SLIP-FLOW}

Ebert and Sparrow [7] studied the slip-flow in rectangular and annular tubes. It was observed that the compressibility effect augments the $\Delta p$ largely due to an augment in viscous shear rather than due to an augment in momentum flux. Choi et al. [8] proposed a new simulation method which incorporates the Navier-Stokes (N-S) solution with a new slip model named Langmuir slip condition. Dongari et al. [9] used a $2^{\text {nd }}$ order slip model to solve the N-S equations for gaseous slip-flow through lengthy micro-channels. Yu and Ameel [10] and Ameel et al. [11] analytically studied laminar slip-flow forced convection (FC) in micro-channels for thermally developing flow subjected to constant wall temperature (CWT) and constant wall heat flux (CWHF) boundary conditions (BCs). Sun et al. [12] numerically studied steady-state 2-dimensional convective heat transfer (CHT) in micro-tubes under CWHF, CWT, and linear variation of wall temperature BCs with slip-flow and temperature jump (TJ) conditions. Arkilic et al. [13] used a slip-flow BC to accurately model the mass flow-pressure relationship. It was found that the no-slip solution of the N-S equations fails to effectively model the momentum transfer from the fluid to the wall of the channel. Hadjiconstantinou and Simek [14] investigated the CHT characteristics for gaseous flow through a 2dimensional micro and nano-channels under hydrodynamically and thermally FDF conditions. Both the slip-flow regime and the transition regime were covered in their research. Renksizbulut et al. [15] numerically investigated the rarefied gas flow and HT in the entry region of rectangular micro-channels with velocity slip (VS) and TJ conditions.

Hettiarachchi et al. [16] numerically studied the laminar slip-flow and HT in rectangular micro-channels having constant temperature walls for thermally and simultaneously developing flows. A correlation for the fully developed friction factor was offered as a function of $K n$ and aspect ratio ( $\alpha$ ). Duan and Muzychka [17] proposed a simple model to calculate the Poiseuille number $(\mathrm{Po})$ for slip-flow in circular and noncircular microchannels. Kavehpour et al. [18] used a 2-dimensional flow and HT model to study gas compressibility and rarefaction in micro-channels assuming a slip-flow regime. It was found that $N u$ and friction coefficient were substantially reduced for slip-flows compared with the continuum flows. Hooman [19] presented a superposition approach to examine FC in micro-ducts subjected to different BCs in the slip-flow regime. Some more investigations have been carried out by Hooman and his research group on the slip-flow HT in micro-channels [20-26]. The effects of VS, TJ, different thermal BCs, duct geometry, fluid property variation, and viscous dissipation (VD) were studied. Rij et al. [27, 28] numerically investigated the influence of VD and rarefaction on CHT through a rectangular microchannel subjected to CWHF and CWT BCs. It was observed that the VS leads to augment in $N u$, however, the TJ leads to lessening $N u$. The viscous heating tends to augment in $\mathrm{Nu}$ for the fluid being cooled and lessen it for the fluid being heated. Beskok et al. [29] investigated the joint effects of compressibility and rarefaction in gas micro-flows in the slip-flow regime. Bahrami et al. [30] investigated the $\Delta p$ for fully-developed, incompressible slip-flow through micro-channels. Zade et al. [31] numerically investigated the special effects of VFP on the flow and HT characteristics of simultaneously developing slip-flow in rectangular micro-channels with CWT and CWHF BCs. Kushwaha and Sahu [32] used the $2^{\text {nd }}$ order VS and TJ BCs to solve the momentum and energy equations along with iso-flux thermal BC at the surface of the micro-pipe.

\section{REVIEW BASED ON VARIATIONS IN FLUID PROPERTIES}

The effect of $\mu(T)$ variation on FC through a circular duct with a CWT BC was firstly proposed by Sieder and Tate [33]. A comprehensive review of previous works associated with the effects of VFP on HT was presented by Kakac [34]. Herwig [35] and Herwig et al. [36] investigated the effect of VFP on momentum and HT by applying an asymptotic method for small HT rates with the CWHF and CWT BCs. Li et al. [37] performed a numerical simulation of FC HT in silicon-based MCHS. It was reported that the thermophysical properties of the liquid can 
significantly influence both the flow and HT in the MCHS. Nonino et al. [38, 39] and Giudice et al. [40] performed a parametric analysis to find the effects of temperature-dependent viscosity (TDV), thermal conductivity (TDTC), and VD on FC in simultaneously developing laminar flow of a liquid in straight ducts. It was confirmed that the effects of TDV and VD cannot be neglected in a wide range of operative conditions of the laminar FC.

Mahulikar and Herwig [41, 42] reported the physical effects due to variations in viscosity and thermal conductivity of liquid on laminar micro-convection. It was concluded that the effects of FPV become highly significant from macro-to-micro-scale convection. Herwig and Mahulikar [43] investigated the variable property effects on the flows through micro-sized channels. Gulhane and Mahulikar [44] numerically investigated the effect of property variations of air in laminar forced micro-convection with the entrance effect. Kumar and Mahulikar [45] numerically investigated the effects of TDV on FDF through a micro-channel. The frictional flow characteristics of water flowing through a circular micro-channel with VFP were investigated by Kumar and Mahulikar [46]. Kumar and Mahulikar [47] investigated the physical effects of VFP on flow and thermal development in micro-channel. It was also observed that the effects of VFP on static gauge pressure drop are highly significant for micro-convective flow. Kumar and Mahulikar [48] investigated the physical effects of VFP on HT and frictional flow characteristics of laminar gas microconvective flow. It was concluded that the physical effects need to be well considered in the applications of laminar gas microconvection based on large temperature gradients, for example, the design of MCHS, and the flow cannot be generally considered as a constant property flow, as in conventional channels.

\section{OBJECTIVE AND SCOPE OF THE INVESTIGATION}

So far the investigators did not explore the effects of $\rho(p, T), \mu(T), k(T)$ and $\mathrm{C}_{\mathrm{p}}(T)$ variations in gaseous slipflow through a MCHS. This aspect stimulates researchers to pinpoint the ultimate changes in fluid flow and HT through a MCHS due to supplementary physical mechanisms induced due to $\rho(p, T), \mu(T), k(T)$ and $\mathrm{C}_{\mathrm{p}}(T)$ variations. Therefore, the present work aims to numerically investigate the effects of these mechanisms on laminar FDF through a MCHS in the slip-flow regime. Incorporation of these mechanisms leads to upgrading the knowledge of microconvection physics within the slip-flow regime. The presented results reveal the influence of these mechanisms in micro-convection characteristics. These results are expected to be useful in the analysis and design of the microscale HF devices.

\section{Mathematical Formulation}

Figure 1 illustrates the schematic diagram of the physical model and the BCs used in this study. Radius $(R)$ of the micro-tube is $25 \mu \mathrm{m}$ and the length $(L)$ of the micro-tube is $2.5 \mathrm{~mm}$. Aspect ratio $=L / D=50$. CWHF BC $\left(q_{\mathrm{w}}^{\prime \prime}\right.$ $\left.=7.5 \mathrm{~W} / \mathrm{cm}^{2}\right)$ is imposed on the outer surface of the MCHS. The values of aspect ratio $(L / D=50)$, heat flux $\left(q_{\mathrm{w}}^{\prime \prime}=\right.$ $\left.7.5 \mathrm{~W} / \mathrm{cm}^{2}\right)$, inlet fluid temperature at the axis of micro-tube $\left(T_{0, \text { in }}=5^{\circ} \mathrm{C}\right)$ and inlet mean axial velocity $\left(u_{\mathrm{m}, \text { in }}=20\right.$ $\mathrm{m} / \mathrm{s}$ ) are chosen on the basis of following reasons: (i) the extreme temperature of air $\left(T_{\mathrm{w}, \mathrm{ex}}\right)$ in the computational field, that should not go above its dissociation temperature $\left(T_{\mathrm{w}, \mathrm{ex}}<2000 \mathrm{~K}\right)$ (ii) the range of $\mathrm{Kn}$ should be in between 0.001 and 1 .

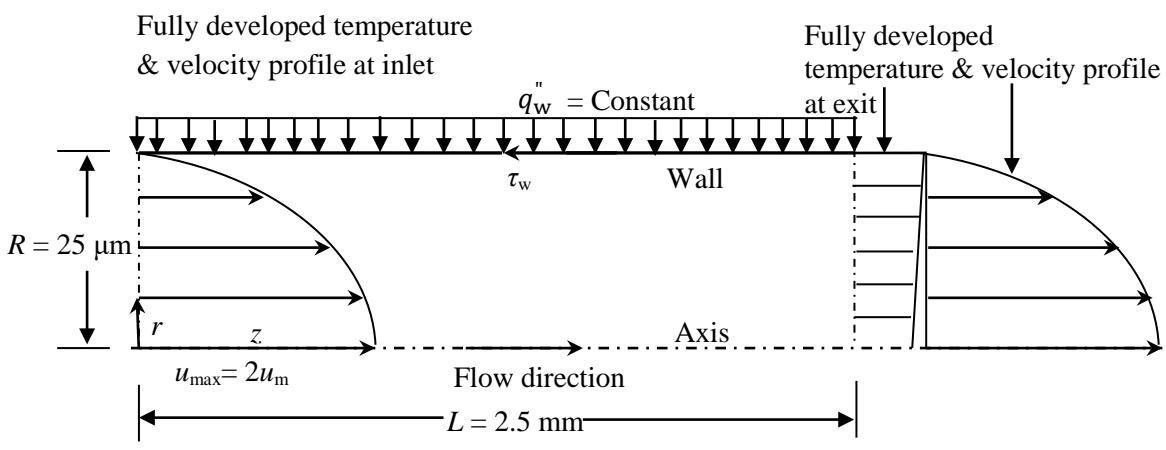

Figure 1. Schematic diagram of the physical model 


\section{Governing Equations}

The 2-dimensional, steady-state, governing equations in cylindrical coordinates (with axisymmetry) are numerically solved for the above field. These equations incorporating $\rho, \mu, k$ and $C_{p}$ variations for convective-flow through a uniform cross-section, in the dimensional form are as follows:

Continuity

$$
\left(v \cdot \frac{\partial \rho}{\partial r}\right)+\rho\left[\left(\frac{\partial u}{\partial z}\right)+\left(\frac{v}{r}\right)+\left(\frac{\partial v}{\partial r}\right)\right]+\left(u \cdot \frac{\partial \rho}{\partial z}\right)=0
$$

Momentum equation [Axial direction]

$$
\rho \cdot\left(v \cdot \frac{\partial u}{\partial r}+u \cdot \frac{\partial u}{\partial z}\right)=-\frac{\partial p}{\partial z}+\left[\left(\frac{\mu}{r}+\frac{\partial \mu}{\partial r}\right) \cdot\left(\frac{\partial u}{\partial r}\right)\right]+\mu \cdot\left[\left(\frac{\partial^{2} u}{\partial z^{2}}\right)+\left(\frac{\partial^{2} u}{\partial r^{2}}\right)\right]+\left(\frac{\partial \mu}{\partial z}\right) \cdot\left(\frac{\partial u}{\partial z}\right)
$$

Momentum equation [Radial direction]

$$
\begin{aligned}
& \rho \cdot\left(v \cdot \frac{\partial v}{\partial r}+u \cdot \frac{\partial v}{\partial z}\right)=-\frac{\partial p}{\partial r}+\left[\left(\frac{\partial \mu}{\partial r}-\frac{\mu}{r}\right)\right] \cdot\left(\frac{v}{r}\right)+\mu \cdot\left[\left(\frac{\partial^{2} v}{\partial z^{2}}\right)+\left(\frac{\partial^{2} v}{\partial r^{2}}\right)\right]+\left(\frac{\partial \mu}{\partial z}\right) \cdot\left(\frac{\partial v}{\partial z}\right)+ \\
& {\left[\left(\frac{\mu}{r}+\frac{\partial \mu}{\partial r}\right) \cdot\left(\frac{\partial v}{\partial r}\right)\right]}
\end{aligned}
$$

Energy equation

$$
\begin{gathered}
\rho \cdot C_{p} \cdot\left(v \cdot \frac{\partial T}{\partial r}+u \cdot \frac{\partial T}{\partial z}\right)=\left[\frac{k}{r}+\frac{\partial k}{\partial r}\right] \cdot\left(\frac{\partial T}{\partial r}\right)+k \cdot\left(\frac{\partial^{2} T}{\partial r^{2}}\right)+\left(\frac{\partial k}{\partial z}\right) \cdot\left(\frac{\partial T}{\partial z}\right)+k \cdot\left(\frac{\partial^{2} T}{\partial z^{2}}\right)+\mu \cdot\left\{\left[\left(\frac{\partial v}{\partial z}+\frac{\partial u}{\partial r}\right)\right]^{2}+\left(\frac{4}{3}\right) \cdot\right. \\
\left.\left[\left(\frac{\partial v}{\partial r}\right)^{2}+\left(\frac{v}{r}\right)^{2}+\left(\frac{\partial u}{\partial z}\right)^{2}-\left(\frac{\partial v}{\partial r}\right) \cdot\left(\frac{v}{r}\right)-\left(\frac{\partial v}{\partial r}\right) \cdot\left(\frac{\partial u}{\partial z}\right)-\left(\frac{v}{r}\right) \cdot\left(\frac{\partial u}{\partial z}\right)\right]\right\}+u \cdot\left(\frac{\partial p}{\partial z}\right)+v \cdot\left(\frac{\partial p}{\partial r}\right)
\end{gathered}
$$

where $\rho$ is the fluid density, $u$ and $v$ are the axial and radial velocities respectively, $z$ and $r$ are the axial and radial directions respectively, $p$ is the pressure, $T$ is the temperature, $\mu, C_{p}$ and $k$ are the dynamic viscosity, specific heat, and thermal conductivity of fluid respectively.

\section{Boundary Conditions}

At the inlet upstream, $z=0, u(r)$ and $T(r)$ profiles are for laminar FDF with constant fluid properties. These profiles are respectively given as [49]; $u(r)=2 u_{\mathrm{m}} \cdot\left[1-(r / R)^{2}\right]$, and $T(r)=T_{0, \mathrm{in}}+\left(q_{\mathrm{w}}^{\prime \prime} \cdot R / k\right) \cdot\left[(r / R)^{2}-\left((r / R)^{4} / 4\right)\right]$. The $T_{0, \text { in }}$ is the inlet gas total temperature at the axis of the tube and $u_{\mathrm{m}}$ is the mean inlet velocity. Inlet BC exposes the role of variation in properties without mixing the entrance effect. From $z=0+$ to $z=L$ (inlet-downstream to exit) property variations are modelled as according to the different cases for non-reacting air.

The pressure at the exit of the tube $\left(p_{\mathrm{ex}}=p_{\mathrm{atm}}=1.01325 \times 10^{5} \mathrm{~N} / \mathrm{m}^{2}\right)$ is equal to standard atmospheric pressure. The symmetric BC is imposed at the axis of the micro-tube; hence, $(\partial u / \partial r)=(\partial p / \partial r)=(\partial T / \partial r)=(\partial \rho / \partial r)=0$. The CWHF BC $\left.[k(\partial T / \partial r)]_{\mathrm{w}}=q_{\mathrm{w}}^{\prime \prime}\right]$ is applied with proper VS and TJ at the wall of the MCHS. According to the slip-flow theory, the VS and TJ at the wall are proportional to normal velocity and temperature gradients, respectively. In the slip flow regime, the N-S and energy equations are solved by including VS and TJ BCs.

\section{NUMERICAL SOLUTION AND VALIDATION}

Equations (1) - (4) are solved numerically along with the ideal gas equation $\left(p=\rho \cdot R_{\mathrm{a}} \cdot T\right)$ by ANSYS FLUENT solver, using the SIMPLE scheme. Second-order upwind advection scheme is used to discretize the convective terms in the momentum and energy equations. Maxwell's models are adopted for VS and TJ phenomena in the FLUENT solver for their simplicity and effectiveness. The low-pressure slip boundary formulation is used for $\mathrm{VS}$ and TJ at the wall. 
VS boundary condition

The $1^{\text {st }}$-order slip BC is used which was presented by Maxwell [50] as:

$$
u_{\mathrm{w}}-u_{\mathrm{a}}=\left(\frac{2-\sigma_{\mathrm{v}}}{\sigma_{\mathrm{v}}}\right) \cdot \lambda \cdot\left(\frac{\partial u}{\partial n}\right)_{\mathrm{w}}
$$

TJ boundary condition

In the same approach, $\mathrm{TJ} \mathrm{BC}$ is used in the $1^{\text {st }}$-order form as:

$$
T_{\mathrm{w}}-T_{\mathrm{a}}=2\left(\frac{2-\sigma_{\mathrm{T}}}{\sigma_{\mathrm{T}}}\right) \cdot \lambda \cdot\left(\frac{\partial T}{\partial n}\right)_{\mathrm{w}}
$$

where, $u_{\mathrm{w}}$ and $T_{\mathrm{w}}$ are the reference wall velocity and temperature, respectively. The $u_{\mathrm{a}}$ and $T_{\mathrm{a}}$ are the air velocity and temperature at the wall, respectively. The $\lambda$ is the mean free path between molecules and $n$ is the coordinate normal to the wall. Here $\sigma_{\mathrm{v}}$ and $\sigma_{\mathrm{T}}$ are the momentum and thermal accommodation coefficients, respectively. The coefficients $\sigma_{\mathrm{v}}$ and $\sigma_{\mathrm{T}}$ describe the interaction of the fluid molecules with the wall. Normally, the values of these coefficients depend on the surface finish, temperature, and velocity at the fluid-wall interface. The values of these coefficients are close to unity for most engineering applications [16]. The value of $\sigma_{\mathrm{v}}$ varies from near zero to unity for specular and diffuse reflections, respectively. In the present investigation, the values of $\sigma_{\mathrm{v}}$ and $\sigma_{\mathrm{T}}$ are the same that is equal to 0.9137 [4].

To simulate the problem, a graded mesh with finer grid density in the vicinity of the inlet and the wall, in order to capture abrupt changes in flow and temperature fields, is used for discretization. The graded mesh comprises 10000 cells [ 200 (in axial direction) $\times 50$ (in radial direction)]. This grid system is conservatively selected on the basis of the grid independence test of final results i.e. $N u_{\mathrm{D}}$ value. The correctness of the numerical solution is checked by validating $N u_{\mathrm{D}}$ results for laminar FDF with constant fluid property for no-slip and no-temperature jump BCs. The results are confirmed with a benchmarked solution $\left(N u_{C P}=4.363\right)$ and show a relative error lower than $0.1 \%$. The solution is deemed converged if the plots of residuals for continuity, $z$ and $r$ momentum, and energy equations are less than $10^{-15}$ or independent of a number of iterations. Additional details relating to the convergence of the solution, the correctness of the numerical results, and validation with benchmark cases for constant fluid properties are reported in [42, 44, and 45].

\section{Variable Physical Properties}

Air is used as a working fluid in the present simulations. Density $(\rho)$ variation is as per ideal gas equation of

state: $p=\rho \cdot R_{\mathrm{a}} \cdot T$. For non-reacting and perfect gas: air, $\mu(T)=\frac{1.462 \times 10^{-6} T^{1.5}}{(T+112)} \mathrm{kg} /(\mathrm{m} \cdot \mathrm{s})$ and $k(T)=\frac{1.9942 \times 10^{-3} T^{1.5}}{(T+112)}$ $\mathrm{W} /(\mathrm{m} \cdot \mathrm{K})$, where, $T$ is in $\mathrm{K}[51]$.

The average value of $C_{p}(=1018.2 \mathrm{~J} / \mathrm{kg} \cdot \mathrm{K})$ is used for the functioning temperature range of $273-550 \mathrm{~K}$, because the deviation from the average value is less than $3 \%$. For the range of $550-2100 \mathrm{~K}, \mathrm{C}_{\mathrm{p}}(T)$ variation is achieved by least-square error $4^{\text {th }}$ order polynomial fit within correctness of $0.12 \%$ in the following form [52]: $\mathrm{C}_{\mathrm{p}}(T)$ $=874.687+0.325431 T-2.07132 \times 10^{-5} T^{2}-6.63386 \times 10^{-8} T^{3}+2.66353 \times 10^{-11} T^{4}$.

\section{RESULTS AND DISCUSSION}

In this section, the effects of VFP on the slip-flow and HT characteristics are presented. Firstly, the governing equations are solved for the case of $\rho(p, T)$ variation with no-slip and with slip boundary conditions. A meaningful comparison between no-slip BC simulations and slip BC simulations is performed for $\rho(p, T)$ variation. The $\rho(p, T)$ variation helps to pinpoint the effects of density variation on slip-flow and HT characteristics independently. Table 1 shows wall temperature $\left(T_{\mathrm{w}}\right)$, bulk mean fluid temperature $\left(T_{\mathrm{m}}\right)$ and various flow properties at different locations of geometry and Table 2 shows dimensionless numbers at inlet and outlet of micro-tube for the slip-flow case. The $R e$ is constant along the flow for $\rho(p, T)$ variation since the mass flux $\left(\rho_{\mathrm{m}} \cdot u_{\mathrm{m}}\right)$ is constant. The 
incorporation of $\mu(T)$ variation reduces $R e$ along the flow since air viscosity increases with temperature and $\left(\rho_{\mathrm{m}} \cdot u_{\mathrm{m}}\right)$ is constant. The Re is insignificantly affected by the incorporation of $k(T)$ variation. A slight increment is observed in $R e$ when $\mathrm{C}_{\mathrm{p}}(T)$ variation is incorporated. This is because the $\mathrm{C}_{\mathrm{p}}(T)$ variation leads to diminishing the rate of augmentation in $T_{\mathrm{m}}$ causes the reduction in the rate of increase in $\mu_{\mathrm{m}}$ and decrease in $\rho_{\mathrm{m}}$. It is also noted that the $u_{\mathrm{m}}$ also reduces due to the incorporation of $\mathrm{C}_{\mathrm{p}}(T)$ variation. In the present research, $M a$ is much less compared to 0.3; hence, compressibility effects can be neglected. The $M a$ increases along the flow for $\rho(p, T)$ variation and this is due to flow acceleration. The $M a$ is insignificantly affected by incorporating $\mu(T)$ and $k(T)$ variations. However, $M a$ reduces when $\mathrm{C}_{\mathrm{p}}(T)$ variation is incorporated due to the lowering of $T_{\mathrm{m}}$ and $u_{\mathrm{m}}$. The density and pressure declines and $K n$ augments along the air heated flow. The value of $K n$ is maximum at the exit of the tube where $\rho$ is lowest. The incorporation of $\mu(T)$ variation increases $K n$, since $R e$ reduces due to an increase in $\mu_{\mathrm{m}}$. The $K n$ is insignificantly affected by the incorporation of $k(T)$ variation. The $K n$ slightly reduces when $\mathrm{C}_{\mathrm{p}}(T)$ variation is incorporated due to a small reduction in $M a$ and a small increment in $R e$.

Figure 2a shows the variation in $N u$ along the flow for $\rho(p, T)$ variation with no-slip and slip BCs. In the case of slip-flow, the presence of the VS and TJ significantly affects the local $N u$ number. The VS enhances the advection near the wall which augments HT however the TJ increases the conduction thermal resistance at the wallfluid interface which degrades HT. Therefore, the collective effect of VS and TJ could augment or degrade the HT depending on their relative magnitude [16]. The effect of VS remains leading throughout the micro-tube resulting in an augment in $\mathrm{Nu}$ throughout the micro-tube as shown in Figure 2a. In the vicinity of the inlet, a rapid increment in $\mathrm{Nu}$ is observed for slip-flow as illustrated in Figure 2. This is due to the presence of large TJ in the locality of the inlet as shown in Figure 3. Figure 3 shows the difference in wall temperature $\left(T_{\mathrm{w}}\right)$ along the flow with no-slip and with slip BC.

Table 1. Wall temperature, bulk mean fluid temperature and flow properties at different locations of geometry for slip-flow

\begin{tabular}{|l|l|l|l|l|}
\hline \multirow{2}{*}{$\begin{array}{l}\text { Combination of properties } \\
\text { variation }\end{array}$} & \multicolumn{3}{|c|}{ Flow properties at various location of geometry } \\
\cline { 2 - 5 } & & Inlet & $z / D=25$ & Outlet \\
\hline$\rho(p, T)$ & $T_{\mathrm{w}}(\mathrm{K})$ & 335.025 & 635.05617 .54 & 951.71 \\
& $T_{\mathrm{m}}(\mathrm{K})$ & 300.32 & 0.5718 & 933.57 \\
& $\rho_{\mathrm{m}}\left(\mathrm{Kg} / \mathrm{m}^{3}\right)$ & 1.1781 & & 0.3765 \\
\hline$\rho(p, T) \& \mu(T)$ & $T_{\mathrm{w}}(\mathrm{K})$ & 335.00 & 635.06 & 951.72 \\
& $T_{\mathrm{m}}(\mathrm{K})$ & 300.32 & 617.55 & 933.57 \\
& $\rho_{\mathrm{m}}\left(\mathrm{Kg} / \mathrm{m}^{3}\right)$ & 1.1781 & 0.5718 & 0.3775 \\
& $\mu_{\mathrm{m}}(\mathrm{kg} /(\mathrm{s} \cdot \mathrm{m}))$ & $1.8454 \times 10^{-05}$ & $3.0754 \times 10^{-05}$ & $4.03 \times 10^{-05}$ \\
\hline$\rho(p, T), \mu(T) \& k(T)$ & $\left.T_{\mathrm{w}} \mathrm{K}\right)$ & 334.66 & 627.01 & 941.13 \\
& $T_{\mathrm{m}}(\mathrm{K})$ & 300.33 & 617.77 & 933.61 \\
& $\rho_{\mathrm{m}}\left(\mathrm{Kg} / \mathrm{m}^{3}\right)$ & 1.1780 & 0.5714 & 0.3780 \\
& $\mu_{\mathrm{m}}(\mathrm{kg} /(\mathrm{s} \cdot \mathrm{m}))$ & $1.8454 \times 10^{-05}$ & $3.0761 \times 10^{-05}$ & $3.9886 \times 10^{-05}$ \\
& $k_{\mathrm{m}}(\mathrm{W} /(\mathrm{m} \cdot \mathrm{K}))$ & 0.0252 & 0.0420 & 0.0545 \\
\hline$\rho(p, T), \mu(T), k(T) \& \mathrm{C}_{\mathrm{p}}(T)$ & $T_{\mathrm{w}}(\mathrm{K})$ & 334.66 & 621.49 & 911.65 \\
& $T_{\mathrm{m}}(\mathrm{K})$ & 300.32 & 612.10 & 904.96 \\
& $\rho_{\mathrm{m}}\left(\mathrm{Kg} / \mathrm{m}^{3}\right)$ & 1.1781 & 0.5767 & 0.3859 \\
& $\mu_{\mathrm{m}}(\mathrm{kg} /(\mathrm{s} \cdot \mathrm{m}))$ & $1.8454 \times 10^{-05}$ & $3.0576 \times 10^{-05}$ & $3.9137 \times 10^{-05}$ \\
& $k_{\mathrm{m}}(\mathrm{W} /(\mathrm{m} \cdot \mathrm{K}))$ & 0.0252 & 0.0418 & 0.0535 \\
& $\mathrm{C}_{\mathrm{pm}}(\mathrm{J} /(\mathrm{kg} \cdot \mathrm{K}))$ & 1018.2 & 1054.65 & 1120.92 \\
\hline
\end{tabular}


Journal of Thermal Engineering, Research Article, Vol. 7, No. 3, pp. 635-649, March, 2021

Table 2. Dimensionless numbers at inlet and outlet of micro-tube for slip-flow

\begin{tabular}{|c|c|c|c|c|c|}
\hline \multicolumn{2}{|c|}{$\begin{array}{c}\text { Combination of properties } \\
\text { variation }\end{array}$} & $\rho(p, T)$ & $\rho(p, T) \& \mu(T)$ & $\rho(p, T), \mu(T) \& k(T)$ & $\begin{array}{c}\rho(p, T), \mu(T), k(T) \& \\
C_{p}(T)\end{array}$ \\
\hline \multirow{2}{*}{$R e$} & inlet & 67 & 64 & 64 & 64 \\
\cline { 2 - 6 } & outlet & 67 & 29 & 29 & 30 \\
\hline \multirow{2}{*}{$M a$} & inlet & 0.0577 & 0.0577 & 0.0577 & 0.0577 \\
\cline { 2 - 6 } & outlet & 0.1016 & 0.1016 & 0.1016 & 0.1 \\
\hline \multirow{2}{*}{$K n$} & inlet & 0.001267 & 0.001337 & 0.001337 & 0.001337 \\
\cline { 2 - 6 } & outlet & 0.002237 & 0.005111 & 0.005112 & 0.004933 \\
\hline \multirow{2}{*}{$N u$} & inlet & 4.353 & 4.355 & 4.261 & 4.261 \\
\cline { 2 - 6 } & outlet & 9.2 & 9.202 & 13.159 & 12.098 \\
\hline
\end{tabular}

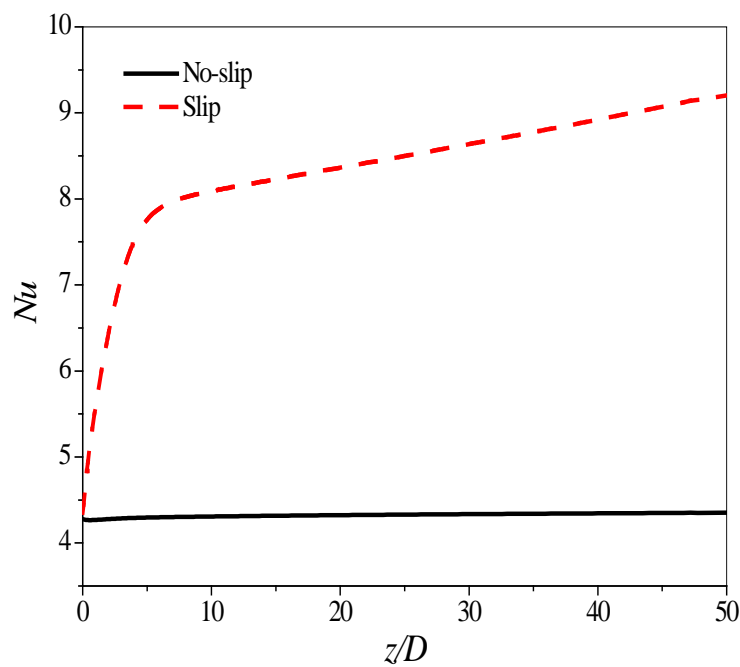

a)

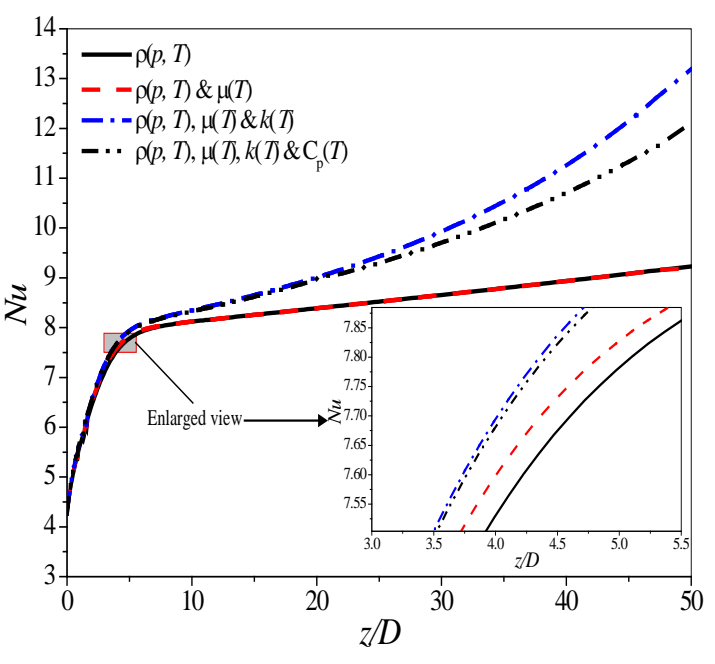

b)

Figure 2. Variation in Nusselt number along the flow. a) due to $\rho(p, T)$ variation, b) due to combination of variation in $\rho(p, T), \mu(T), k(T)$, and $C_{p}(T)$ for slip-flow case

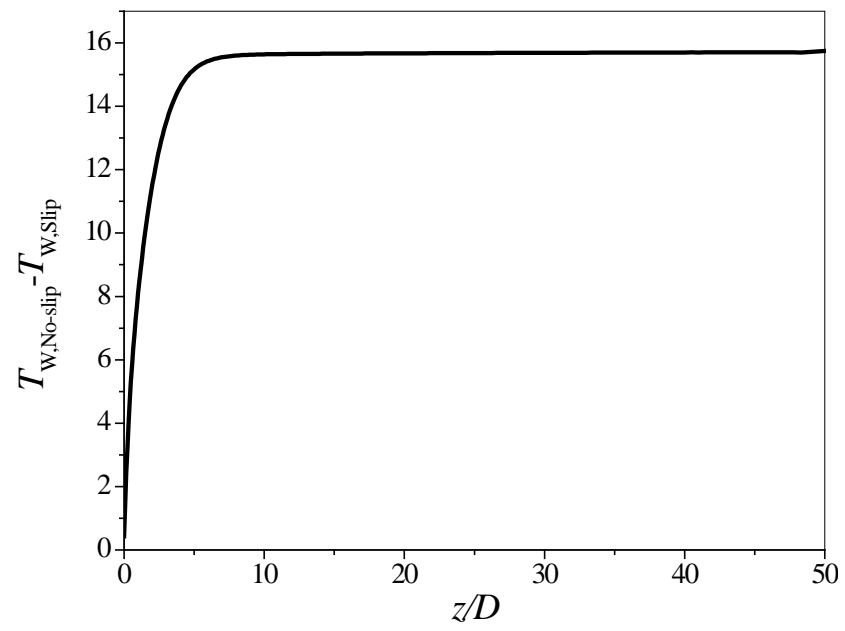

Figure 3. Variation in ( $\left.T_{\mathrm{w}, \mathrm{No}-\mathrm{slip}}-T_{\mathrm{w}, \mathrm{Slip}}\right)$ along the flow for $\rho(p, T)$ variation 
The variation in $\mathrm{Nu}$ along the flow for the case of slip-flow is shown in Figure 2b, for four different cases: (i) $\rho(p, T)$ (ii) $\rho(p, T) \& \mu(T)$ (iii) $\rho(p, T), \mu(T) \& k(T)$ (iv) $\rho(p, T), \mu(T), k(T), \& C_{p}(T)$. The effect of $\rho(p, T)$ variation is to flatten $u(r)$ profile which promotes faster-moving particles close to the wall which considerably enhances the convection. The $\rho(p, T)$ variation develops radially outward flow which increases thermal resistance in the fluid, thereby degrading the convection [6]. Figure 4a shows the $u(r, z)$ profile for $\rho(p, T)$ variation with no-slip and slip BCs at an axial location $z / D=5$. Incorporation of slip-flow with $\rho(p, T)$ variation flattens $u(r)$ profile, which reduces axial velocity at the centerline of the micro-tube. This leads to larger mass flux near to the wall which enhances $\mathrm{Nu}$ as shown in Figure $2 b$.

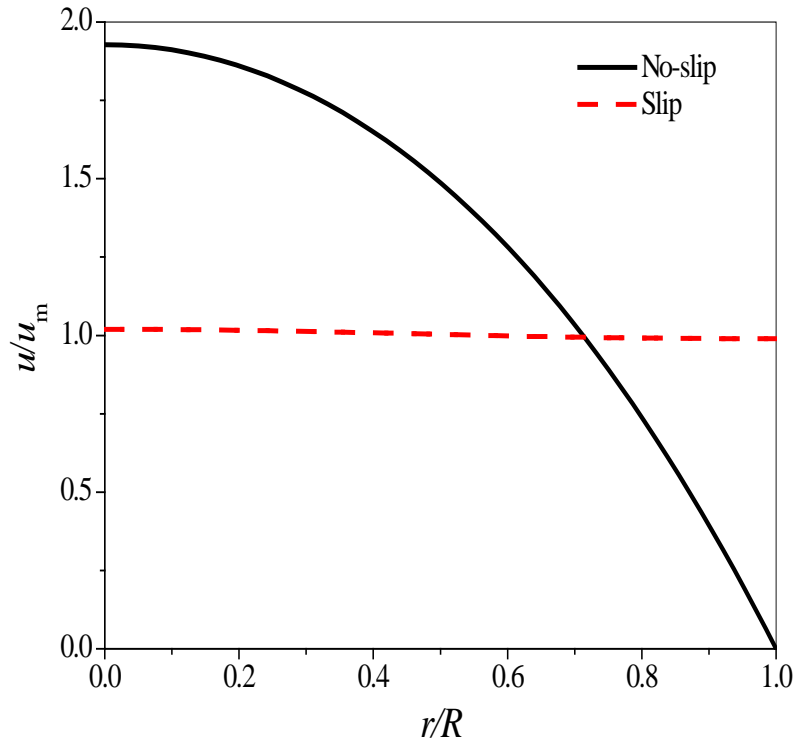

a)

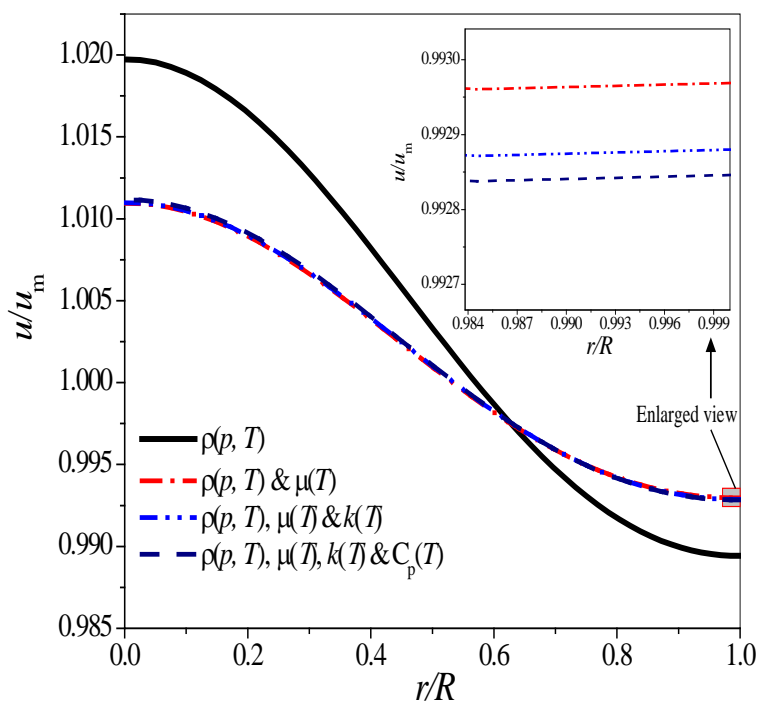

b)

Figure 4. Radial variation of axial velocity at $z / D=5$. a) due to $\rho(p, T)$ variation, b) due to combination of variation in $\rho(p, T), \mu(T), k(T)$, and $C_{p}(T)$ for slip-flow case

Incorporating $\mu(T)$ variation slightly enhances $N u$ along the flow as shown in Figure $2 \mathrm{~b}$ and given in Table 2. The $\mu(T)$ variation slightly flattens $u(r)$ profile (see Figure $4 \mathrm{~b}$ ) which promotes faster-moving particles close to the wall which slightly enhances the convection. Figure 5 shows the $\rho$ gradients over the cross-section at $z / D=5$. In the case of heated air, $\rho(r)$ profile is an inverted ' $U$ ' shape and lower $\rho$ closer to the wall is less effective in heat transport which degrades convection. The $\rho(r)$ profile is a converse of $T(r)$ profile as shown in Figure 6 and ' $U$ ' shape $\rho(r)$ profile augments convection. For slip-flow, the higher $\rho$ closer to the wall is more effective in heat transport which augments $N u$. The higher $\rho$ closer to the wall is due to the lower temperature near to the wall as shown in Figure 6a. Incorporation of $\mu(T)$ variation slightly increases $\rho$ closer to the wall which slightly augments $N u$. This slight increment in $\rho$ near the wall is due to the slight reduction in the temperature of fluid near the wall as shown in Figure 6b. 


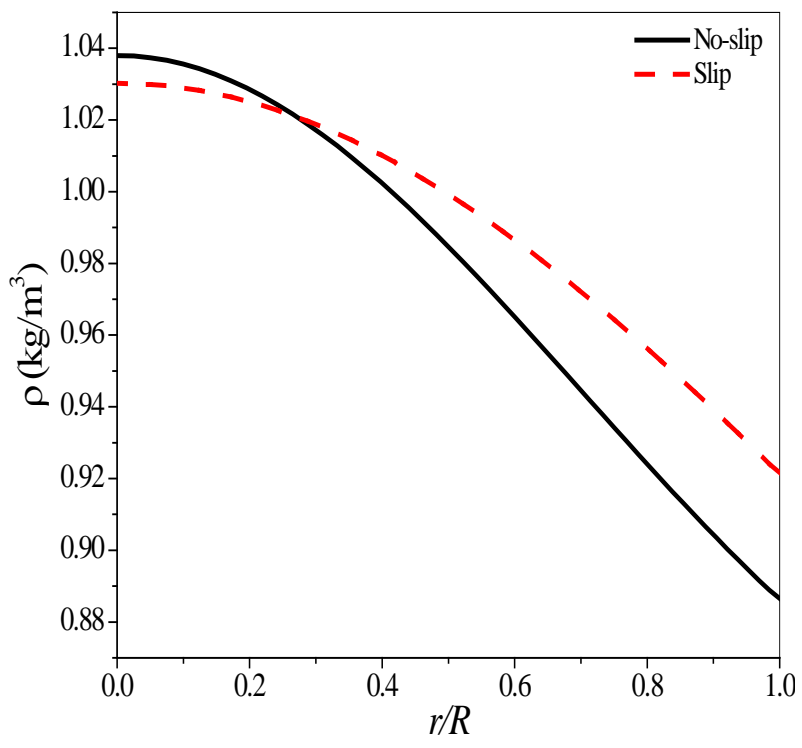

a)

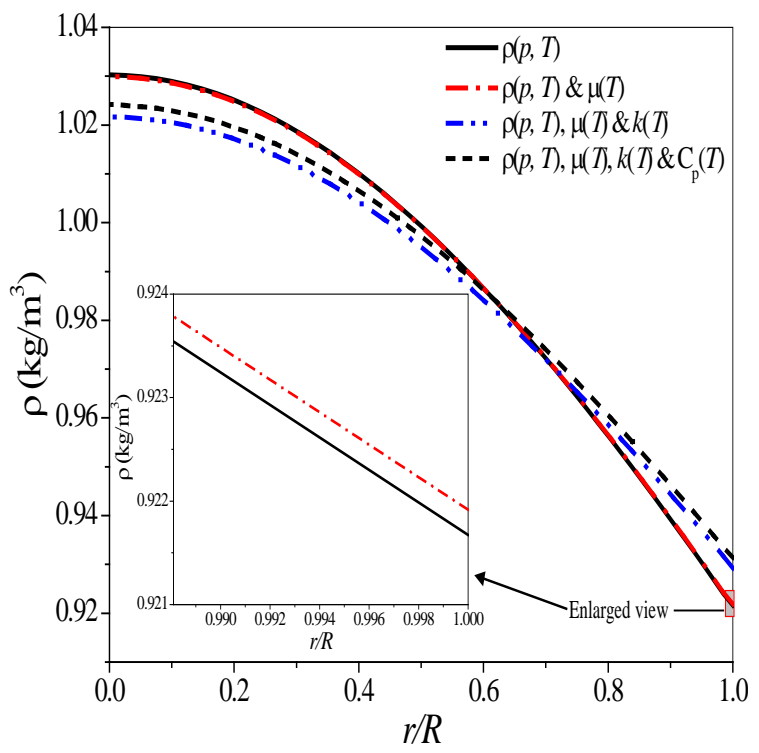

b)

Figure 5. Radial variation of density at $z / D=5$. a) due to $\rho(p, T)$ variation, b) due to combination of variation in $\rho(p$, $T), \mu(T), k(T)$, and $\mathrm{C}_{\mathrm{p}}(T)$ for slip-flow case

Incorporation of $k(T)$ variation highly augments $N u$ as given in Table 2 and shown in Figure $2 \mathrm{~b}$. The $k(r)$ profile is $U$-shaped due to a higher temperature near to the wall. This leads to higher $k$-fluid near to the wall which is more effective to transfer more heat compared to higher $k$-fluid near to the centerline. Therefore, $k(r)$ variation leads to enhance $N u_{\mathrm{D}}$ for air heated case. The $k(z)$ variation is considerably greater than $k(r)$ variation. The $k(z)$ variation induces axial conduction for $q_{\mathrm{w}}^{\prime \prime}=$ Constant BC, which considerably affects gas micro convection [44]. Heat flow at cross-section is given by, $q_{\mathrm{w}}^{\prime \prime}=k_{\mathrm{w}} \cdot(\partial T / \partial r)_{\mathrm{w}}$. For constant $q_{\mathrm{w}}^{\prime \prime}$, the augmenting $k_{\mathrm{w}}$ along the heated flow declines the corresponding temperature gradient near to the wall as shown in Figure 6b. This leads to a higher $\rho$ closer to the wall (see Figure $5 b$ ) which is more effective in heat transport, thereby promoting convection. Therefore, higher $\rho$ and higher $k$-fluid near to the wall lead to augment in $N u$.

Incorporation of $\mathrm{C}_{\mathrm{p}}(T)$ variation lessens the $N u$ as shown in Figure $2 \mathrm{~b}$ and given in Table 2. Incorporating $\mathrm{C}_{\mathrm{p}}(T)$ variation increases $\mathrm{C}_{\mathrm{p}}$ closer to the wall which causes a lessening in $T_{\mathrm{w}}$ for a given $q_{\mathrm{w}}^{\prime \prime}$ as illustrated in Figures $6 \mathrm{~b}$ and 7a. Figure 7b shows that the rate of change of $T_{\mathrm{m}}$ is lower for the case of $\mathrm{C}_{\mathrm{p}}(T)$ variation only than for other cases of property variation. This is due to the increase in $\mathrm{C}_{\mathrm{p}}(T)$ that lowers $u_{\mathrm{m}}$ (as $u_{\mathrm{m}} \propto T_{\mathrm{m}} / p_{\mathrm{m}}$ ) [6]. Incorporating $\mathrm{C}_{\mathrm{p}}(T)$ variation leads to lessening the rate of augmentation in $T_{\mathrm{m}}$ and $T_{\mathrm{w}}$ as shown in Figure 7 and given in Table 1. Therefore, lower- $k$ fluid exists near to the wall as compared to the case of $\rho(p, T), \mu(T) \& k(T)$ variation, which lowers the convection. The value of $\left(T_{\mathrm{w}}-T_{\mathrm{m}}\right)$ for $\rho(p, T), \mu(T), k(T) \& \mathrm{C}_{\mathrm{p}}(T)$ variation is more as compared to the case of $\rho(p, T), \mu(T) \& k(T)$ variation. Therefore, the incorporation of $\mathrm{C}_{\mathrm{p}}(T)$ variation diminishes $N u$ as compared to the case of $\rho(p, T), \mu(T) \& k(T)$ variation. 


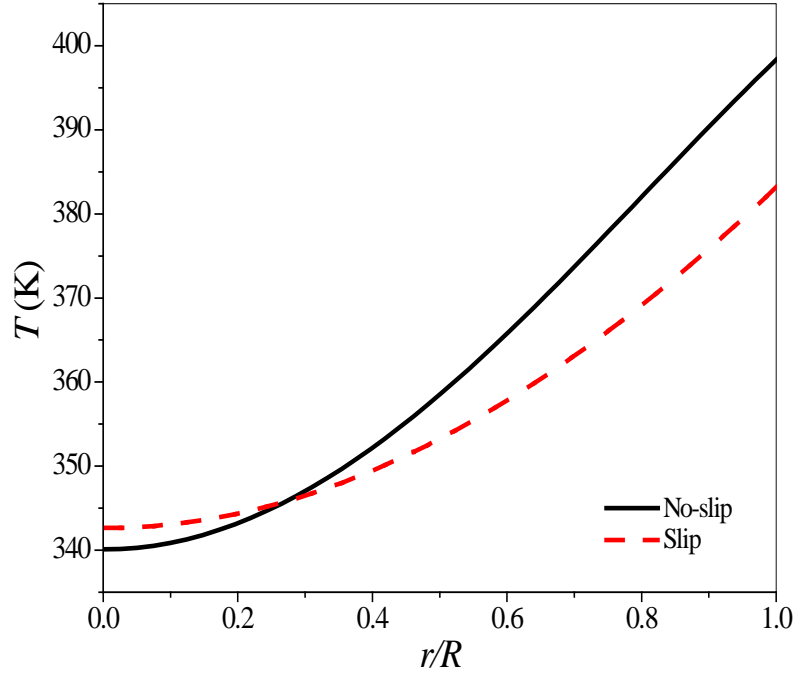

a)

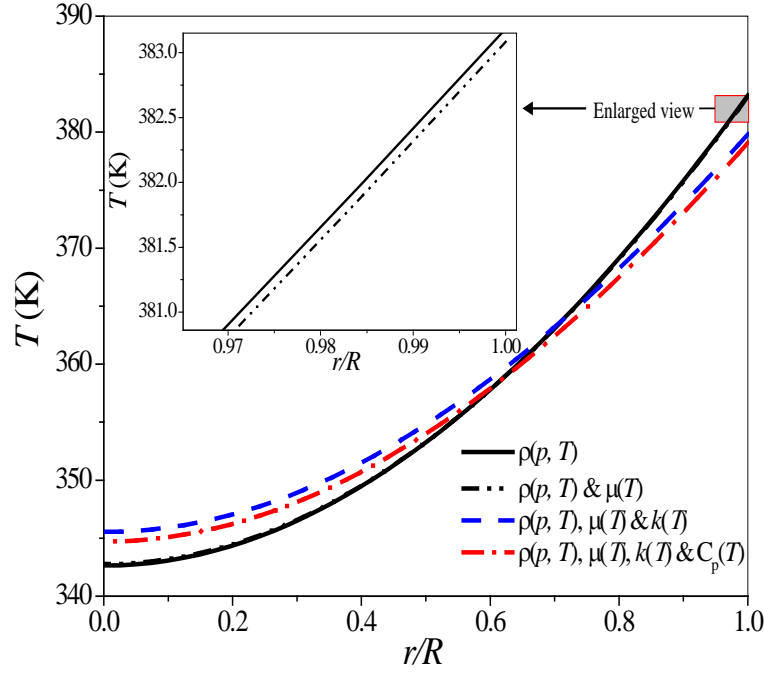

b)

Figure 6. Radial variation of static temperature at $z / D=5$. a) due to $\rho(p, T)$ variation, b) due to combination of variation in $\rho(p, T), \mu(T), k(T)$, and $C_{p}(T)$ for slip-flow case

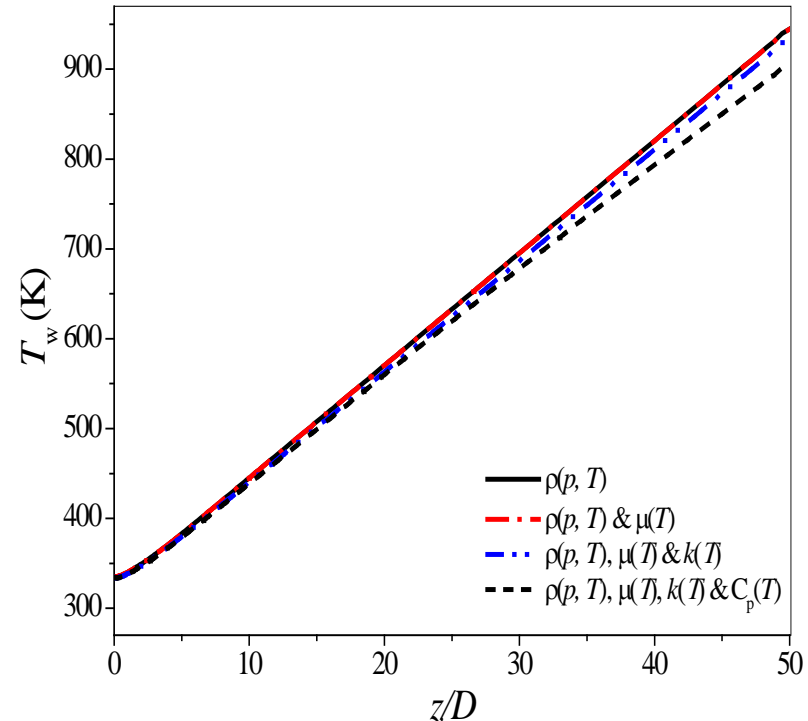

a)

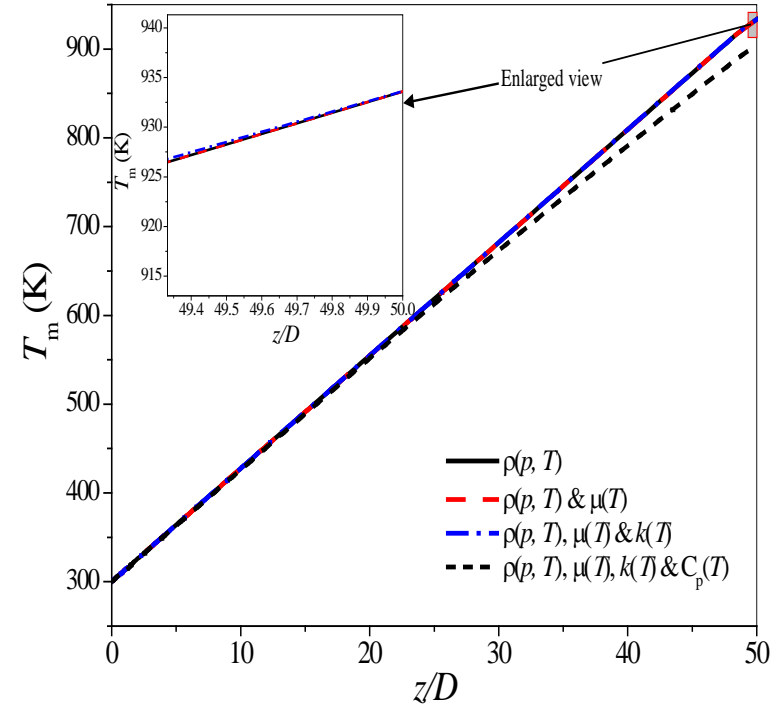

b)

Figure 7. Effect of variation in fluid property on a) $T_{\mathrm{w}}$, b) $T_{\mathrm{m}}$, along the flow, for the case of slip-flow

Figure 8a shows the gauge static pressure drop $\left(\Delta p_{\mathrm{g}}\right)$ along the flow for $\rho(p, T)$ variation with no-slip and slip conditions. The $\Delta p_{\mathrm{g}}$ is calculated as: $\Delta p_{\mathrm{g}}(\mathrm{z})=\Delta p_{\mathrm{m}}(\mathrm{z})-p_{\mathrm{ex}}(L)$, where $p_{\mathrm{m}}$ is the cross-sectional average pressure. It is noted that the $\Delta p_{\mathrm{g}}$ is nonlinear along the flow which is attributed to the role of temperature-sensitivity of gas density $\mathrm{S}_{\rho \mathrm{T}}(=\partial \rho / \partial T)$, rather than the widely reported role of compressibility associated with pressure-sensitivity of gas density $\mathrm{S}_{\mathrm{\rho p}}(=\partial \rho / \partial p)$ [53]. The $\Delta p_{\mathrm{g}}$ due to $\rho(p, T)$ variation is 24967.6 Pa with the no-slip BC, which nearly reduces to $778.247 \mathrm{~Pa}$ with slip BC. Figure $8 \mathrm{~b}$ shows the $\Delta p_{\mathrm{g}}$ along the flow due to a combination of variation in $\rho(p$, $T), \mu(T), k(T)$, and $\mathrm{C}_{\mathrm{p}}(T)$ for the slip-flow case. It is observed that the incorporation of $\mu(T)$ and $k(T)$ variations insignificantly affects the $\Delta p_{\mathrm{g}}$. However, the incorporation of $\mathrm{C}_{\mathrm{p}}(T)$ variation significantly affects the $\Delta p_{\mathrm{g}}$. This is because the incorporation of $\mathrm{C}_{\mathrm{p}}(T)$ variation lessens $\mu_{\mathrm{m}}$ due to a reduction in $T_{\mathrm{m}}$. 


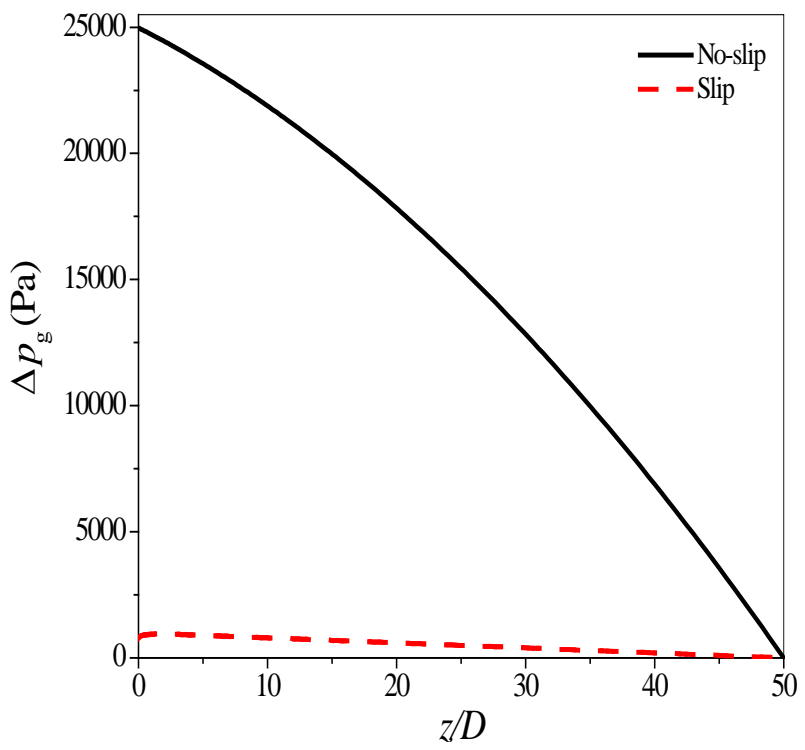

a)

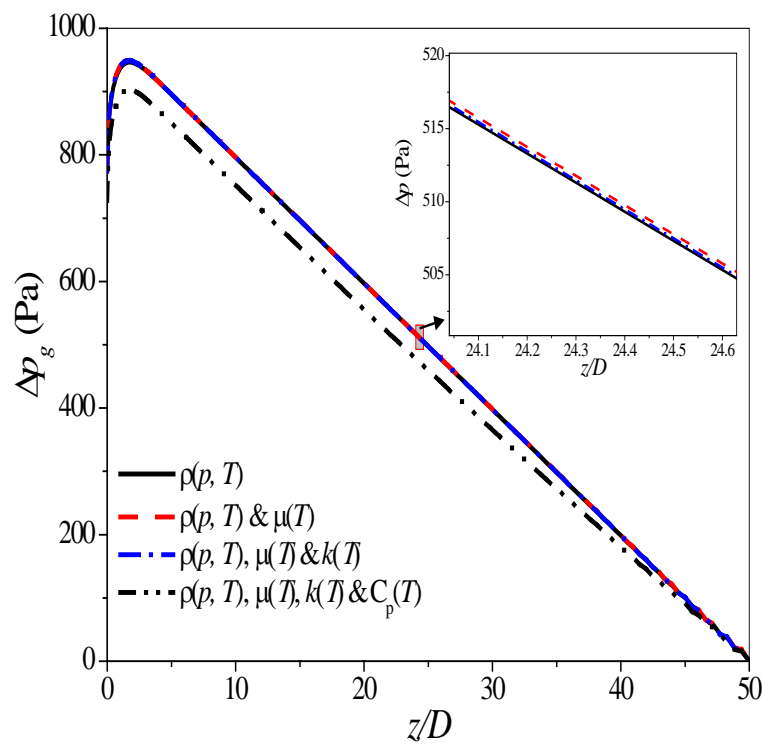

b)

Figure 8. Variation in gauge static pressure drop along the flow. a) due to $\rho(p, T)$ variation, b) due to combination of variation in $\rho(p, T), \mu(T), k(T)$, and $C_{p}(T)$ for slip-flow case

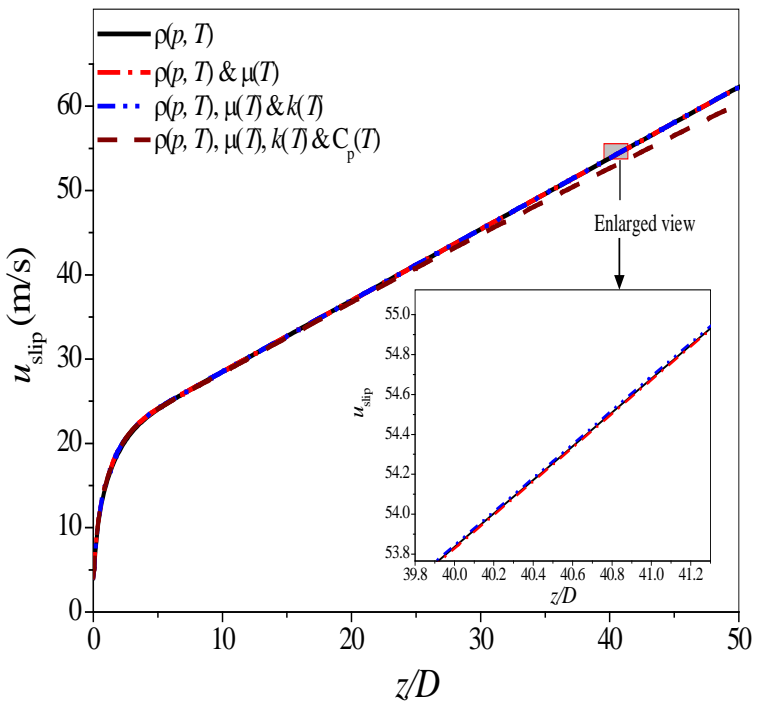

Figure 9. Variation of slip velocity along the flow due to combination of variation in $\rho(p, T), \mu(T), k(T)$, and $C_{p}(T)$

Figure 9 shows the variation of slip velocity $\left(u_{\text {slip }}\right)$ along the flow due to a combination of variation in $\rho(p$, $T), \mu(T), k(T)$, and $C_{p}(T)$. The $u_{\text {slip }}$ increases along the flow. It is noted that the $u_{\text {slip }}$ is trivially affected by the incorporation of $\mu(T)$ and $k(T)$ variation. This is because the incorporation of $\mu(T)$ and $k(T)$ variation trivially affect the $T_{\mathrm{m}}$. However, the $u_{\text {slip }}$ is significantly affected by incorporating $\mathrm{C}_{\mathrm{p}}(T)$ variation. This is because the incorporation of $\mathrm{C}_{\mathrm{p}}(T)$ variation reduces $\mu_{\mathrm{m}}$ due to a reduction in $T_{\mathrm{m}}$.

\section{CONCLUSIONS}

Physical effects induced in micro-convective gaseous slip-flow due to variations in gas properties with CWHF BC are studied numerically for hydrodynamically and thermally developed flow. The flow and energy 
equations subjected to proper VS and TJ at the wall are solved in a 2-dimensional domain using the finite-volume method. In the case of slip-flow, the presence of the VS and TJ significantly affects the local Nu number. The four different cases of VFP are studied in order to investigate their effects individually. The $\rho(p, T)$ variation flattens the $u(r)$ profile which promotes faster-moving particles close to the wall which significantly enhances $N u$. The incorporation of $\mu(T)$ variation slightly enhances $N u$ along the flow. Incorporation of $k(T)$ variation highly augments $N u$ due to higher $\rho$ and higher $k$ fluid near to the wall and the incorporation of $\mathrm{C}_{\mathrm{p}}(T)$ variation drops $N u$ due to lower $k$ fluid near to the wall. The $\Delta p_{\mathrm{g}}$ significantly deviates from no-slip to slip condition. The incorporation of $\mu(T)$ and $k(T)$ variations trivially affects the $\Delta p_{\mathrm{g}}$ and slip velocity. However, the incorporation of $\mathrm{C}_{\mathrm{p}}(T)$ variation significantly affects the $\Delta p_{\mathrm{g}}$ and slip velocity.

\section{ACKNOWLEDGMENTS}

The author would like to thank Prof. Shripad P. Mahulikar, Department of Aerospace Engineering, Indian Institute of Technology Bombay and Dr. R. S. Bharj, Associate Professor, Department of Mechanical Engineering, Dr. B. R. Ambedkar National Institute of Technology Jalandhar, India, for the valuable suggestions and comments.

\section{NOMENCLATURE}

c $\quad$ Velocity of sound $(\sqrt{\gamma \cdot R \cdot T}$ m $), \mathrm{m} / \mathrm{s}$

$\mathrm{C}_{\mathrm{p}}(T) \quad$ Temperature dependent specific heat at constant pressure, $\mathrm{J} / \mathrm{kgK}$

$D \quad$ Diameter of micro-tube, $\mathrm{m}$

$k(T) \quad$ Temperature dependent thermal conductivity, W/mK

$L \quad$ Length of micro-tube, $m$

$q_{\mathrm{w}}^{\prime \prime} \quad$ Heat flux at wall, $\mathrm{W} / \mathrm{m}^{2}$

$R \quad$ Radius of micro-tube, $\mathrm{m}$

$T_{\mathrm{m}} \quad$ Bulk mean fluid temperature, $\mathrm{K}$

$T_{\mathrm{w}} \quad$ Wall temperature, $\mathrm{K}$

$u_{\text {slip }} \quad$ Slip velocity, $\mathrm{m} / \mathrm{s}$

$T(r) \quad$ Temperature profile in radial direction

$u(r) \quad$ Axial velocity profile in radial direction

Greek symbols

$\mathrm{S}_{\rho p} \quad$ Pressure-sensitivity of gas density $(\partial \rho / \partial p)$

$\mathrm{S}_{\rho \mathrm{T}} \quad$ Temperature-sensitivity of gas density $(\partial \rho / \partial T)$

$\Delta p \quad$ Pressure drop, Pa

$\mu(T) \quad$ Temperature dependent viscosity, $\mathrm{Ns} / \mathrm{m}^{2}$

$\rho(p, T) \quad$ Pressure and temperature dependent density, $\mathrm{kg} / \mathrm{m}^{3}$

$\gamma \quad$ Specific heat ratio

Non-dimensional numbers

$K n \quad$ Knudsen number $\left(\lambda / D_{h}\right)$

Ma Mach number $\left(u_{\mathrm{m}} / \mathrm{c}\right)$

$\mathrm{Nu} \quad$ Nusselt number $\left(h \cdot D / k_{\mathrm{m}}\right)$

Po $\quad$ Poiseuille number $\left(f \cdot R e_{\mathrm{D}}\right)$

Re Reynolds number $\left(\rho_{\mathrm{m}} \cdot u_{\mathrm{m}} \cdot D / \mu_{\mathrm{m}}\right)$

\section{Subscripts}

CP Constant properties

D Based on diameter

ex Value at outlet

in $\quad$ Value at inlet

$\mathrm{m} \quad$ Mean value of properties calculated at bulk mean temperature, $T_{\mathrm{m}}$

VP Variable properties

w Condition at wall 
Journal of Thermal Engineering, Research Article, Vol. 7, No. 3, pp. 635-649, March, 2021

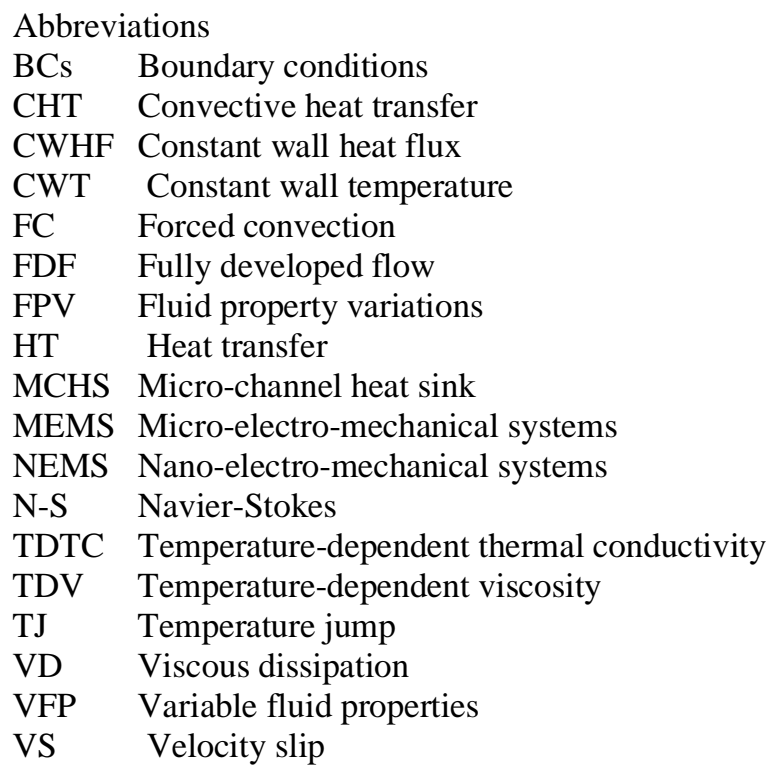

\section{REFERENCES}

[1] Mahulikar SP, Herwig H, Hausner O. Study of gas microconvection for synthesis of rarefaction and nonrarefaction effects. J Microelectromech S 2007;16:1543-56. doi:10.1109/JMEMS.2007.908434.

[2] Gad-el-Hak M. The fluid mechanics of microdevices - the Freeman scholar lecture. J Fluids Eng 1999;121:5-33. doi:10.1115/1.2822013.

[3] Kandlikar S, Garimella S, Li D, Colin S, King MR. Heat Transfer and Fluid Flow in Minichannels and Microchannels. Elsevier; 2005.

[4] Karniadakis G, Beskok A, Aluru N. Microflows and Nanoflows: Fundamentals and Simulation. Springer Science \& Business Media; 2006.

[5] Megregany M, Nagarkar P, Senturia SD, Lang JH. Operation of microfabricated harmonic and ordinary side-drive motors. In IEEE Proceedings on Micro Electro Mechanical Systems, An Investigation of Micro Structures, Sensors, Actuators, Machines and Robots. 1990. pp. 1-8.

[6] Gulhane NP, Mahulikar SP. Numerical study of compressible convective heat transfer with variations in all fluid properties. Int J Therm Sci 2010;49:786-96. doi:10.1016/j.ijthermalsci.2009.11.001.

[7] Ebert WA, Sparrow EM. Slip flow in rectangular and annular ducts. J Basic Eng 1965;87: 1018-1024. doi:10.1115/1.3650793.

[8] Choi HI, Lee D, Maeng JS. Computation of slip flow in microchannels using Langmuir slip condition. Numer Heat Transf Part A Appl 2003;44:59-71. doi:10.1080/713838170.

[9] Dongari N, Agrawal A, Agrawal A. Analytical solution of gaseous slip flow in long microchannels. Int J Heat Mass Transf 2007;50:3411-21. doi:10.1016/j.ijheatmasstransfer.2007.01.048.

[10] Yu S, Ameel TA. Slip-flow heat transfer in rectangular microchannels. Int J Heat Mass Transf 2001;44:4225-34. doi:10.1016/S0017-9310(01)00075-8.

[11] Ameel TA, Wang X, Barron RF, Warrington RO. Laminar forced convection in a circular tube with constant heat flux and slip flow. Microscale Thermophysical Engineering 1997;1:303-20. doi:10.1080/108939597200160.

[12] Sun W, Kakac S, Yazicioglu AG. A numerical study of single-phase convective heat transfer in microtubes for slip flow. Int J Therm Sci 2007;46:1084-94. doi:10.1016/j.ijthermalsci.2007.01.020.

[13] Arkilic EB, Schmidt MA, Breuer KS. Gaseous slip flow in long microchannels. J Microelectromech S 1997;6:167-78. doi:10.1109/84.585795.

[14] Hadjiconstantinou NG, Simek O. Constant-wall-temperature Nusselt number in micro and nano-channels. J Heat Transfer 2002;124:356-64. doi:10.1115/1.1447931. 
[15] Renksizbulut M, Niazmand H, Tercan G. Slip-flow and heat transfer in rectangular microchannels with constant wall temperature. Int J Therm Sci 2006;45:870-81. doi:10.1016/j.ijthermalsci.2005.12.008.

[16] Hettiarachchi HM, Golubovic M, Worek WM, Minkowycz WJ. Three-dimensional laminar slip-flow and heat transfer in a rectangular microchannel with constant wall temperature. Int J Heat Mass Transf 2008;51:5088-96. doi:10.1016/j.ijheatmasstransfer.2008.02.049.

[17] Duan Z, Muzychka YS. Slip flow in the hydrodynamic entrance region of circular and noncircular microchannels. J Fluids Eng 2010;132: 011201. doi:10.1115/1.4000692.

[18] Kavehpour HP, Faghri M, Asako Y. Effects of compressibility and rarefaction on gaseous flows in microchannels. Numer Heat Transf Part A Appl 1997;32:677-96. doi:10.1080/10407789708913912.

[19] Hooman K. A superposition approach to study slip-flow forced convection in straight microchannels of uniform but arbitrary cross-section. Int J Heat Mass Transf 2008;51:3753-62. doi:10.1016/j.ijheatmasstransfer.2007.12.014.

[20] Hooman K. Entropy generation for microscale forced convection: effects of different thermal boundary conditions, velocity slip, temperature jump, viscous dissipation, and duct geometry. Int Commun Heat Mass 2007;34:945-57. doi:10.1016/j.icheatmasstransfer.2007.05.019.

[21] Hooman K. Heat transfer and entropy generation for forced convection through a microduct of rectangular cross-section: effects of velocity slip, temperature jump, and duct geometry. Int Commun Heat Mass 2008;35(9):1065-8. doi:10.1016/j.icheatmasstransfer.2008.05.015.

[22] Hooman K. Slip flow forced convection in a microporous duct of rectangular cross-section. Appl Therm Eng 2009;29:1012-9. doi:10.1016/j.applthermaleng.2008.05.007.

[23] Hooman K, Hooman F, Famouri M. Scaling effects for flow in micro-channels: variable property, viscous heating, velocity slip, and temperature jump. Int Commun Heat Mass 2009;36:192-6. doi:10.1016/j.icheatmasstransfer.2008.10.003.

[24] Hooman K, Ejlali A. Effects of viscous heating, fluid property variation, velocity slip, and temperature jump on convection through parallel plate and circular microchannels. Int Commun Heat Mass 2010;37(1):34-8. doi:10.1016/j.icheatmasstransfer.2009.09.011.

[25] Languri EM, Hooman K. Slip flow forced convection in a microchannel with semi-circular cross-section. Int Commun Heat Mass 2011;38:139-43. doi:10.1016/j.icheatmasstransfer.2010.11.021.

[26] Hooman K, Li J, Dahari M. Slip flow forced convection through microducts of arbitrary cross-section: Heat and momentum analogy. Int Commun Heat Mass 2016;71:176-9. doi:10.1016/j.icheatmasstransfer.2015.12.027.

[27] Van Rij J, Ameel $\mathrm{T}$, Harman $\mathrm{T}$. The effect of viscous dissipation and rarefaction on rectangular microchannel convective heat transfer. Int J Therm Sci 2009;48:271-81. doi:10.1016/j.ijthermalsci.2008.07.010.

[28] Van Rij J, Ameel T, Harman T. An evaluation of secondary effects on microchannel frictional and convective heat transfer characteristics. Int J Heat Mass Transf 2009;52:2792-801. doi:10.1016/j.ijheatmasstransfer.2009.01.001.

[29] Beskok A, Karniadakis GE, Trimmer W. Rarefaction and compressibility effects in gas microflows. J Fluids Eng 1996;118: 448-56. doi:10.1115/1.2817779.

[30] Bahrami M, Tamayol A, Taheri P. Slip-flow pressure drop in microchannels of general cross section. J Fluids Eng 2009;131: 031201. doi:10.1115/1.3059699.

[31] Zade AQ, Renksizbulut M, Friedman J. Heat transfer characteristics of developing gaseous slip-flow in rectangular microchannels with variable physical properties. Int J Heat Fluid Fl 2011;32:117-27. doi:10.1016/j.ijheatfluidflow.2010.10.004.

[32] Kushwaha HM, Sahu SK. Analysis of gaseous flow in a micropipe with second order velocity slip and temperature jump boundary conditions. Heat Mass Transfer 2014;50:1649-59. doi:10.1007/s00231-0141368-3.

[33] Sieder EN, Tate GE. Heat transfer and pressure drop of liquids in tubes. Ind Eng Chem 1936;28:1429-35. doi:10.1021/ie50324a027. 
[34] Kakac S. The effect of temperature-dependent fluid properties on convective heat transfer. Handbook of Single-Phase Convective Heat Transfer. Wiley, New York, 1987. Chapter 18.

[35] Herwig $\mathrm{H}$. The effect of variable properties on momentum and heat transfer in a tube with constant heat flux across the wall. Int J Heat Mass Transf 1985;28:423-31. doi:10.1016/0017-9310(85)90075-4.

[36] Herwig H, Voigt M, Bauhaus FJ. The effect of variable properties on momentum and heat transfer in a tube with constant wall temperature. Int J Heat Mass Transf 1989;32:1907-15. doi:10.1016/00179310(89)90160-9.

[37] Li J, Peterson GP, Cheng P. Three-dimensional analysis of heat transfer in a micro-heat sink with single phase flow. Int J Heat Mass Transf 2004;47:4215-31. doi:10.1016/j.ijheatmasstransfer.2004.04.018.

[38] Nonino C, Del Giudice S, Savino S. Temperature dependent viscosity effects on laminar forced convection in the entrance region of straight ducts. Int $\mathrm{J}$ Heat Mass Transf 2006;49:4469-81. doi:10.1016/j.ijheatmasstransfer.2006.05.021.

[39] Nonino C, Del Giudice S, Savino S. Temperature-dependent viscosity and viscous dissipation effects in microchannel flows with uniform wall heat flux. Heat Transfer Eng 2010;31:682-91. doi:10.1080/01457630903466670.

[40] Del Giudice S, Savino S, Nonino C. Temperature dependent viscosity and thermal conductivity effects on the laminar forced convection in straight microchannels. J Heat Transfer 2013;135:101003. doi:10.1115/1.4024496.

[41] Mahulikar SP, Herwig H. Theoretical investigation of scaling effects from macro-to-microscale convection due to variations in incompressible fluid properties. Appl Phys Lett 2005;86:014105. doi:10.1063/1.1845597.

[42] Mahulikar SP, Herwig H. Physical effects in laminar microconvection due to variations in incompressible fluid properties. Phys Fluids 2006;18:073601. doi:10.1063/1.2210027.

[43] Herwig H, Mahulikar SP. Variable property effects in single-phase incompressible flows through microchannels. Int J Therm Sci 2006;45:977-81. doi:10.1016/j.ijthermalsci.2006.01.002.

[44] Gulhane NP, Mahulikar SP. Variations in gas properties in laminar micro-convection with entrance effect. Int J Heat Mass Transf 2009;52:1980-90. doi:10.1016/j.ijheatmasstransfer.2008.08.037.

[45] Kumar R, Mahulikar SP. Effect of temperature-dependent viscosity variation on fully developed laminar microconvective flow. Int J Therm Sci 2015;98:179-91. doi:10.1016/j.ijthermalsci.2015.07.011.

[46] Kumar R, Mahulikar SP. Frictional flow characteristics of microconvective flow for variable fluid properties. Fluid Dyn Res 2015;47:065501. doi:10.1088/0169-5983/47/6/065501.

[47] Kumar R, Mahulikar SP. Physical effects of variable thermophysical fluid properties on flow and thermal development in micro-channel. Heat Transfer Eng 2018;39:374-90. doi:10.1080/01457632.2017.1305841.

[48] Kumar R, Mahulikar SP. Physical effects of variable fluid properties on laminar gas microconvective flow. Heat Tran Asian Res 2017;46:1029-40. doi:10.1002/htj.21256.

[49] Bird RB, Stewart WE, Lightfoot EN. Transport Phenomena (revised second ed.) New York: John Wiley \& Sons; 2007.

[50] Maxwell JC. VII. On stresses in rarified gases arising from inequalities of temperature. Philosophical Transactions of the Royal Society of London. 1879;31:231-56. doi:10.1098/rstl.1879.0067.

[51] Anderson Jr, JD. Hypersonic and high-temperature gas dynamics. Singapore: McGraw Hill; 2006.

[52] Eckert ER, Drake Jr RM. Analysis of Heat and Mass Transfer. Washington: Hemisphere; 1987.

[53] Mahulikar SP, Gulhane NP, Pradhan SD, Hrisheekesh K, Prabhu SV. Pressure drop characteristics in continuum-based laminar compressible microconvective flow. Nanoscale Microscale Thermophys Eng 2012;16:181-97. doi:10.1080/15567265.2012.683934. 